\title{
Severe Thyrotoxicosis Does Not Accelerate 1a-Hydroxylation of 25-Hydroxyvitamin D3 in Dogs. Experimental Study
}

\author{
Christos Georgiou Velentzas ${ }^{1,2}$ \\ ${ }^{1}$ Toronto Western Hospital, Toronto, Canada; ${ }^{2}$ University of Athens, Athens, Greece. \\ Email: impression713@yahoo.gr
}

Received September $18^{\text {th }}, 2013$; revised October $17^{\text {th }}, 2013$; accepted November $14^{\text {th }}, 2013$

Copyright (C) 2013 Christos Georgiou Velentzas. This is an open access article distributed under the Creative Commons Attribution License, which permits unrestricted use, distribution, and reproduction in any medium, provided the original work is properly cited.

\begin{abstract}
Two healthy dogs weighing $18 \mathrm{~kg}$ and $13 \mathrm{~kg}$ each received an intravenous injection of $7 \mu \mathrm{g} / \mathrm{kg} 25$-hydroxyvitamin D3 $\left(25 \mathrm{OHD}_{3}\right)$. Subsequently, they were blood-sampled in order to determine the plasma levels of $25(\mathrm{OH}) \mathrm{D}_{3}$ over 4-hourly time intervals and for a time period of 24 hours. After a period of 18 days since the last blood sampling, the animals were brought to a hyperthyroid state and the intravenous injection of $7 \mu \mathrm{g} / \mathrm{kg} 25 \mathrm{OHD}_{3}$ was repeated. Blood sampling was performed every 4 hours and over a time period of 24 hours in order to determine the levels of $25 \mathrm{OHD}_{3}$. The graphic plotting of plasma levels of $25 \mathrm{OHD}_{3}$ in the euthyroid state did not differ from that in the hyperthyroid state. This finding in dog animal experimentation is indicative that the increased levels of thyroid hormones did not affect the activity of CYP27B1 and CYP24A1 enzymes that are related to the catabolism of $25 \mathrm{OHD}_{3}$ over a minimum of 24 hours period.
\end{abstract}

Keywords: Thyrotoxicosis; Vitamin D; Dogs

\section{Introduction}

Thyrotoxicosis represents a morbid condition that gradually deprives the body of Vitamin D. In thyrotoxicosis, the plasma levels of 1,25-dihydroxyvitamin D (1, $\left.25(\mathrm{OH})_{2} \mathrm{D}\right)$ are depressed. Moreover, hydroxylation of Vitamin D on $\mathrm{C} 25$ position for the production of 25-hydroxyvitamin-D (25OHD) is accelerated resulting in low plasma levels of Vitamin D [1-3]. The accelerated hydroxylation of Vitamin D on C25 position in cases of thyrotoxicosis is due to the stimulation of liver microsomal enzymes (CYP27A1, CYP2J3, CYP2R1, CYP3A4) by the thyroid hormones. In addition, the pathogenesis of the attenuated levels of $1,25(\mathrm{OH})_{2} \mathrm{D}$ has not been fully understood. Parathormone, serum calcium and phosphorus, CYP enzymes (CYP24A1, CYP27B1) VDR, steroid and xenobiotic receptor (SXR) have all been reported as being involved in the pathogenesis of the "depressed" levels of $1,25(\mathrm{OH})_{2} \mathrm{D}$ in thyrotoxicosis [4].

In the following research study, we have attempted to investigate the influence of thyroxine on the CYP27B1 enzyme, which through hydroxylation of $25 \mathrm{OHD}$ leads to the production of $1,25(\mathrm{OH})_{2} \mathrm{D}$.

\section{Materials}

The study involves two dogs weighing $18 \mathrm{~kg}$ (dog "W") and $13 \mathrm{~kg}$ (dog "B"), respectively. These dogs initially were examined by a veterinary physician and were then placed in a specially designated area for experimentation (Vivarium) measuring $1 \times 1 \times 2 \mathrm{~m}$ with conditions of $20^{\circ} \mathrm{C}-24^{\circ} \mathrm{C}$ temperature, good ventilation and lighting systems and with excellent hygiene conditions. The animals received standardised food and water (adlibidum). They were weighed daily and their pulse was monitored and ranged between $90-100 / \mathrm{min}$. The animals remained in the designated areas for monitoring and for adaptation to this new environment and personnel for a time period of 9 days. Table 1 shows the biochemical findings in the blood of the animals.

\section{Methods}

The animals received an intravenous injection of $7 \mu \mathrm{g} / \mathrm{kg}$ $25 \mathrm{OHD}_{3}$ (approximately $5000 \mathrm{iu}$ ) and were subsequently 
blood sampled every 4 hours and for a total time period of 24 hours ${ }^{1}$. Eighteen days after the last blood sampling, the dogs were administered thyroxine at a dose of $0.5 \mathrm{mg} / \mathrm{kg}$ of body weight (IM-intramuscularly) ${ }^{2}$. Ten days later the animals were in a severe hyperthyroid state, as confirmed by physical examination (severe tachycardia that could not be clinically monitored, aggression, tremor, muscle weakness, constant barking, thirst, weight loss of $1-2 \mathrm{~kg}$ etc) and mainly by the thyroid function tests that showed low values prior to the start of the intervention and high values at the end of the study (comparisons made with human subject values). During the thyrotoxicosis phase and due to the severe hyperstimulation the animals received large doses of chlorpromazine, diazepam, nembutale and b-blockers, since the animals showed great resistance to these substances. At the hyperthyroid phase, the animals had an intravenous injection of $7 \mu \mathrm{g} / \mathrm{kg}$ $25 \mathrm{OHD}_{3}$ and were blood sampled at 4-hourly intervals for a time period of 24 hours.

\section{Results}

Euthyroid phase: The intravenous infusion of $7 \mu \mathrm{g} / \mathrm{kg}$ of body weight $25 \mathrm{OHD}_{3}$ to dog " $\mathrm{W}$ " gave the following values: minimum of $103.3 \mathrm{ng} / \mathrm{ml}$ (20th hour), maximum of $179.60 \mathrm{ng} / \mathrm{ml}$ (4th hour) and mean value of $123.9 \pm$ 28.2. The intravenous infusion of $7 \mu \mathrm{g} / \mathrm{kg}$ of body weight to dog "B" gave the following values: minimum of 98.8 $\mathrm{ng} / \mathrm{ml}$ (4th hour), maximum of 118.6 (20th hour) and

\footnotetext{
${ }^{1}$ The substance $25 \mathrm{OHD}_{3}$ that was intravenously injected to the dogs is manufactured by "Upjohn" company; a Standard graph is plotted for the determination of blood levels. A solution was prepared with this substance mixed in propylene-glycol containing $100 \mu \mathrm{g} / \mathrm{ml}$. The solution was sterilised through infiltration with millipore paper.

${ }^{2}$ The induction of hyperthyroidism in dogs is extremely difficult and laborious because animals are significantly tolerant and resistant to thyroxine (half-life time of thyroxine in dogs is 6.9 hours) [5]. The way to induce hyperthyroidism in dogs can be found in reports and publications over previous decades, such as these of De Bodo and Sinkoff 1953 [6], Brewster et al. 1956 [7], Piatnek and Olson 1961 [5], PitanekLennsen and Olson 1967 [8], Frey HMM 1967 [9]). The oral administration of thyroxine to the dogs and at a daily dose of $0.4-5$. Omg was ineffective. Subsequently, we applied the method of De Bodo and Sinkoff 1953 [5] as it is considered to be the most rapid and effective method.

In special plastic sterile tubes (Cooke Provial Cooke Laboratory Products) with a sealing cap, we put $10 \mathrm{mg}$ of thyroxine [L-thyroxin sodium salt -1 gr $\mathrm{BDH}$ Biochemicals $\left.-\mathrm{C}_{6} \mathrm{H}_{2}(\mathrm{OH})\right] \mathrm{C}_{6} \mathrm{H}_{2} \mathrm{CH}(\mathrm{NH} 2)$ COONa), Specific rotation (a) $20^{\circ} \mathrm{C}+16^{\circ} \mathrm{C}$ to $-20^{\circ} \mathrm{C} 2 \%$ in acidified ethane. Loss on drying at $105^{\circ} \mathrm{C}$.

The tubes were then sealed with a cap and were placed in the freezer. Whenever needed to perform an IM injection of thyroxine, $2.5 \mathrm{ml}$ of alcohol was injected in a tube via a syringe (Absolut alcohol-Abort Laboratories North Chicago 25 ampl $2 \mathrm{ml}$ sterilized). Thyroxine powder was rapidly dissolved in the alcohol. For further dilution, $1.5-2 \mathrm{ml}$ of water for injection was aspirated.

According to the properties of the substance, thyroxine is dissolvable in alcohol at 1:250 and in water at 1:600. This thyroxine solution is unstable and therefore the IM injection was done without delay and under aseptic conditions to the animal's thigh. In order to bring the dogs to a hyperthyroid state it was necessary to administer thyroxine at a dose of $0.25-0.52 \mathrm{mg} / \mathrm{kg}$.
}

mean value of $108.3 \pm 6.7$.

Hyperthyroid phase: The intravenous infusion of the same dose of $25 \mathrm{OHD}_{3}$ per kg of body weight to dog "W" gave the following values: minimum of $109 \mathrm{ng} / \mathrm{ml}$ (20th hour), maximum of $150.5 \mathrm{ng} / \mathrm{ml}$ (12th hour) and mean value of $125 \pm 16.4$. The intravenous infusion to dog " $\mathrm{B}$ " gave the following values: minimum of $112.4 \mathrm{ng} / \mathrm{ml}$ (12th hour), maximum of $119.0 \mathrm{ng} / \mathrm{ml}$ (20th hour), and mean value of $116 \pm 2.4$. The values of $25 \mathrm{OHD}_{3}$ in both animals and measured 4-hourly in an euthyroid state and in a hyperthyroid state are demonstrated in Table 2 and Figure 1. There was no statistically significant difference between them $(p=N S)$. The thyroxine values at the euthyroid phase and the rest of the findings that are related to the thyroxine metabolism are displayed in Table 3. The health of the animals had completely recovered one month after the last blood sampling.

\section{Discussion}

The plasma levels of $25 \mathrm{OHD}_{3}$ during the hyperthyroid phase of the animals showed no difference in comparison to those levels in the euthyroid phase. This indirectly shows that the values of $25 \mathrm{OHD}_{3}$ were not deranged to the hydroxylated products $\left(1,25(\mathrm{OH})_{2} \mathrm{D}_{3}\right.$ and $\left.24,25(\mathrm{OH})_{2} \mathrm{D}_{3}\right)$ under the effect of the increased levels of thyroid hormones.

The thyrotoxicosis of the animals was indisputable as shown from the thyroid function tests (Table 3) and the clinical presentation of animals.

It is possible that the significantly raised levels of the

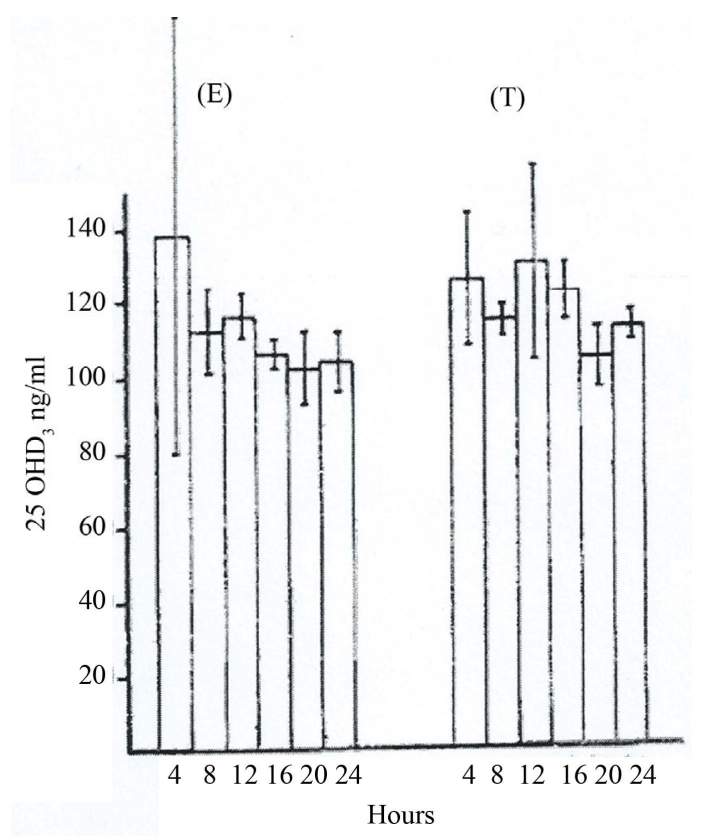

Figure 1. Plasma levels of $25 \mathrm{OHD}_{3}$ in both dogs in the Euthyroid phase (E) and the Thyrotoxic phase (T) after the intravenous infusion of $7 \mu \mathrm{g} / \mathrm{kg} \mathrm{25OHD}$. 
Table 1. Biochemical findings of dogs in the euthyroid phase (E) and the thyrotoxic phase (T).

\begin{tabular}{cccccccccccc}
\hline & $\mathrm{Na}$ & $\mathrm{K}$ & $\mathrm{CI}$ & $\mathrm{CO}_{2}$ & Prot & $\mathrm{Ca}$ & $\mathrm{P}$ & Uric acid & Cr. & Bilir. & LDH \\
\hline $\mathrm{WE}$ & 138 & 4.9 & 99 & 19.5 & 6.7 & 9.3 & 2.8 & 5.5 & 0.9 & 0.8 & 288 \\
$\mathrm{WT}$ & 144 & 4.1 & 113 & 11.0 & 5.8 & 9.1 & 8.2 & 1.3 & 0.8 & 0.1 & 535 \\
$\mathrm{BE}$ & 152 & 4.6 & 114 & 15.5 & 5.9 & 10.4 & 4.3 & 1.0 & 0.9 & 0.3 & 430 \\
$\mathrm{BT}$ & 152 & 4.8 & 114 & 15.0 & 5.4 & 9.9 & 9.3 & 1.5 & 1.1 & 0.3 & 433 \\
\hline
\end{tabular}

Table 2. Mean values of $25 \mathrm{OHD}_{3}$ of both animals on a 4-hourly basis in the euthyroid and hyperthyroid phase. There was no statistically significant difference between the values in the euthyroid and hyperthyroid phase.

\begin{tabular}{cccccc}
\hline \multicolumn{7}{c}{ Euthyroid phase } \\
\hline $\mathbf{4}$ hours & $\mathbf{8}$ & $\mathbf{1 2}$ & $\mathbf{1 6}$ & $\mathbf{2 0}$ & $\mathbf{2 4}$ \\
\hline 139.2 & 119.9 & 116.3 & 106.9 & 110.9 & 117.0 \\
\pm 57.1 & \pm 10.5 & \pm 5.5 & \pm 3.1 & \pm 10.8 & \pm 7.0 \\
& & \multicolumn{2}{c}{ Hyperthyroid phase } & 114.0 & 136.3 \\
126.5 & 114.0 & 131.4 & 122.1 & \pm 7.0 & \pm 2.7 \\
\hline 17.1 & \pm 3.5 & \pm 26.9 & \pm 8.8 & & \\
\end{tabular}

Table 3. Thyroid gland function values in the euthyroid phase (E) and the thyrotoxic phase (T).

\begin{tabular}{|c|c|c|c|c|c|c|}
\hline & RiaT4 & RiaT3 & RT3U & yGT & ALP & Chol. \\
\hline & $\mu \mathrm{g} \%$ & ng\% & $\%$ & $\mathbf{U} / \mathbf{L}$ & $\mathbf{m u} / \mathbf{m l}$ & $\mathrm{mg} \%$ \\
\hline WE & 1.0 & 50 & 61.0 & 1 & 52 & - \\
\hline WT & $>24$ & $>800$ & 65.7 & 8 & 208 & 119 \\
\hline BE & 2.4 & 60 & 60.1 & 0 & 75 & 178 \\
\hline BT & $>24$ & $>800$ & 62.6 & 3 & 111 & 127 \\
\hline
\end{tabular}

thyroid hormones in comparison to their levels during the euthyroid phase $(2 \mu \mathrm{g} \%)$, and also the suppressive medication given during the hyperthyroid phase, may have affected in a negative way the enzyme activity or may have almost completely suppressed their function. The dose of $7 \mu \mathrm{g} / \mathrm{kg} 25 \mathrm{OHD}_{3}(\sim 3600-5000)$ is most likely excessive for animals weighing 13 and $18 \mathrm{~kg}$. Nevertheless, it was taken into consideration that the plasma levels of $25 \mathrm{OHD}_{3}$ in dogs has a wide variation ranging from 5 to $70 \mathrm{ng} / \mathrm{ml}$ depending on the respective reference range and also on the type of food being received [10]. This dose gave high plasma levels of $25 \mathrm{OHD}_{3}$ in the animals both during the euthyroid and hyperthyroid phase. These levels never exceeded the toxic levels which for humans are defined as above the limit of 150, 206, 490, 690 and 468 $\mathrm{ng} / \mathrm{ml}$ [11], and the serum calcium was similar in the euthyroid and hyperthyroid state.

Due to the lack of data about the physiology of vitamin $\mathrm{D}$ in dogs, it was not possible to evaluate the role of thyroid hormones on the metabolites and final products of vitamin D.

This study focused on the function of CYP27B1 cytochrome, which contains the 1a-hydroxylase enzyme which hydroxylates $25 \mathrm{OHD}_{3}$ in the a-position.

\section{Conclusions}

The significantly increased levels of thyroid hormones did not affect the increased plasma levels of $25 \mathrm{OHD}_{3}$ in the dogs that were tested 4-hourly and for a time period of 24 hours. These findings lead us to the following assumptions:

1) The excessive increase in the plasma levels of thyroid hormones inhibited the activity of the hydroxylating enzymes of $25 \mathrm{OHD}_{3}$ in the dogs, in contrast to the stimulation of the liver microsomal enzymes (CYP27A1, CYP3A4, CYP2J3, CYP2R1 which in humans induce the rapid hydroxylation of vitamin $\mathrm{D}$ ) in position 25 .

2) It is necessary to allow for more time beyond 24 hours to have a more definite result. 
3) The significant increase in supply of $25 \mathrm{OHD}_{3}$ to the CYP27B1 enzyme inhibited or slowed down the enzyme activity.

4) The thyroid hormones have no effect on the hydroxylating enzymes of 25OHD in dogs. FGF23-clotho reduces the blood levels of $1,25(\mathrm{OH})_{2} \mathrm{D}_{3}$ [12]. There is a lack of data in literature for the correlation of thyroxine and the axis of osteoblasts-osteocytes-PTH-FGF23-clotho and $1,25(\mathrm{OH})_{2} \mathrm{D}$.

\section{Addendum}

In 1633 Galileo Galilei quoted the historical phrase "Eppure si muove (still it moves, and yet it moves) when he was forced from "Holy Inquisition" to recant his belief that the earth moves around the sun (The event was first reported in English print in 1757 by Giuseppe Baretti) [13]. A minor yet similar event occurred to me as well. In my case, the "Holy Inquisition" was my research study that forced me to state that the increased levels of thyroid hormones in dogs do not influence the metabolism of $25 \mathrm{OHD}_{3}$. On the contrary, I believe that the increased blood levels of thyroid hormones in the body accelerate the catabolism of vitamin D to give the end products of calcitroic acid and lactones [14]. In favour of this theory are: 1) the accelerated hydroxylation of Vitamin D on $\mathrm{C} 25$ position in thyrotoxicosis, 2) the depressed levels of $1,25(\mathrm{OH})_{2} \mathrm{D}_{3}$ again in thyrotoxicosis, 3) the increased $1,25(\mathrm{OH})_{2} \mathrm{D}_{3}$ blood levels in hypothyroidism [15]. I believe that a more detailed investigation in human subjects will clarify these issues in the future.

\section{REFERENCES}

[1] R. Bouillon, E. Muls and P. De Moor, "Influence of Thyroid Function on the Serum Concentration of 1,25 Dihydroxyvitamin D," Journal of Clinical Endocrinology \& Metabolism, Vol. 51, No. 4, 1980, pp. 793-797. http://dx.doi.org/10.1210/jcem-51-4-793

[2] A. Mac Farlane, E. B. Mawer, J. Berry and J. Hann, "Vitamin D Metabolism in Hyperthyroidism," Clinical Endocrinology, Vol. 17, No. 1, 1982, pp. 51-59.

[3] C. G. Velentzas, "The Hydroxylation of Vitamin D on C25 in Thyrotoxicosis: The Role of the Activity of Microsomal Liver Enzymes," International Journal of Clinical Medicine, Vol. 3, No. 4, 2012, pp. 295-299.

\section{http://dx.doi.org/10.4236/ijcm.2012.34057}

[4] C. G. Velentzas, "Vitamin D and Thyroid Hormones," In: S. R. Malone, Ed., Vitamin D Nutrition Side Effects and Supplements, 2009, pp. 175-184.

[5] D. A. Piatnek and R. E. Olson, "Experimental Hyperthyroidism in Dogs and Effect of Salivariectomy," American Journal of Physiology, Vol. 201, 1961, pp. 723-728.

[6] R. C. De Bodo and M. W. Sinkoff, "The Role of Growth Hormone in Carbohydrate Metabolism," Annals of the New York Academy of Sciences, Vol. 57, 1953, p. 23. http://dx.doi.org/10.1111/j.1749-6632.1953.tb36385.x

[7] W. R. Brewster, J. P. Isaacs, P. F. Osgood and Th. L. King, "The Hemodynamic and Metabolic Interrelationships in the Activity of Epinephrine, Norepinephrine and the Thyroid Hormones," Circulation, Vol. 13, 1956, p. 1. http://dx.doi.org/10.1161/01.CIR.13.1.1

[8] D. Piatnek-Leunssen and R. E. Olson, "Cardiac Failure in the Dog as a Consequence of Exogenous Hyperthyroidism," Circulation Research, Vol. 20, 1967, p. 242. http://dx.doi.org/10.1161/01.RES.20.2.242

[9] H. M. M. Frey, "Peripheral Circulatory and Metabolic Consequences of Thyrotoxicosis. Blood Flow and Oxy gen Consumption of Resting and Working Skeletal Muscle in Experimental Thyrotoxicosis in the Dog," Scandinavian Journal of Clinical \& Laboratory Investigation, Vol. 19, No. 1, 1967, p. 4. http://dx.doi.org/10.3109/00365516709093476

[10] W. Reece, "Duke's Physiology of Domestic Animals," 12th Edition, Cornell University Press, New York, 2004, p. 565 .

[11] J. G. Haddad and T. C. B. Stamp, "Circulating 25 Hydroxyvitamin D in Man," American Journal of Medicine, Vol. 57, No. 1, 1974, pp. 57-62. http://dx.doi.org/10.1016/0002-9343(74)90768-2

[12] O. Makoto Kuro, "Overview of the FGF-23-Klotho Axis," Pediatric Nephrology, Vol. 25, No. 4, 2010, pp. 583-590.

[13] S. Drake, "Galileo at Work: His Scientific Biography," Mineola (NY) Dover, 2003.

[14] D. E. Prosser and J. Glenville, "Enzymes Involved in the Activation and Inactivation of Vitamin D," Trends in Biochemical Sciences, Vol. 29, No. 12, 2004, pp. 664-673. http://dx.doi.org/10.1016/j.tibs.2004.10.005

[15] G. A. Brent, R. Larsen and T. F. Davies, "Hypothyroidism and Thyroiditis," In Williams Textbook of Endocrinology, 11th Edition, 2008, p. 382. 